\title{
Family meals and adolescents: what have we learned from Project EAT (Eating Among Teens)?
}

\author{
Dianne Neumark-Sztainer ${ }^{1, *}$, Nicole I Larson ${ }^{1}$, Jayne A Fulkerson ${ }^{2}$, Marla E Eisenberg ${ }^{3}$ \\ and Mary Story ${ }^{1}$ \\ 'Division of Epidemiology \& Community Health, School of Public Health, University of Minnesota, 1300 South \\ Second Street - Suite 300, Minneapolis, MN 55454, USA: ${ }^{2}$ School of Nursing, University of Minnesota, \\ Minneapolis, MN, USA: ${ }^{3}$ Pediatrics and Adolescent Health, Department of Pediatrics, University of Minnesota, \\ Minneapolis, MN, USA
}

Submitted 3 June 2009: Accepted 6 January 2010: First published online 10 February 2010

\begin{abstract}
Objective: The purpose of the present paper is to provide an integrated overview of the research methodology and key findings from a decade of research on family meals as part of Project EAT (Eating Among Teens), a large, populationbased study of adolescents.

Design: Focus groups conducted with 141 middle-school and high-school adolescents suggested the importance of family meals in influencing adolescents' food choices. These findings led to the inclusion of questions on family meals in the Project EAT-I survey, completed by 4746 middle-school and high-school students, and in the Project EAT-II longitudinal survey, completed by 2516 of the original participants five years later. A subset of 902 parents also participated in telephone interviews as part of Project EAT-I.

Results: Findings indicate that many adolescents and parents view family meals in a positive light, but there is great diversity in the context and frequency of family meal patterns in the homes of adolescents. Findings further suggest that family meals may have benefits in terms of dietary intake, disordered eating behaviours, substance use and psychosocial health.

Conclusions: Findings from Project EAT, in conjunction with other research studies on family meals, suggest the importance of working with families to increase the frequency and improve the quality of family meals. Further research is needed in order to elucidate the pathways that underpin the relationships between family meals and health outcomes. Suggestions for a future research agenda based on what was learned from Project EAT are provided.
\end{abstract}

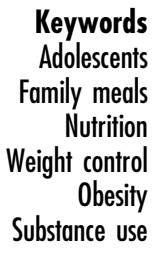

Keywords

Adolescents

Nutrition

Obesity

Substance use
Adolescence is a critical developmental period characterized by major physical changes in growth and development as well as many psychosocial changes as young people seek increased autonomy from their parents and begin to spend more time with their peers ${ }^{(1,2)}$. Adolescents are at risk for various problematic behaviours and health outcomes including inadequate dietary intake ${ }^{(3,4)}$, unhealthy weight-control behaviours ${ }^{(5)}$, excess weight gain $^{(6)}$, substance-use behaviours $^{(7)}$ and psychosocial issues, such as low self-esteem and depression ${ }^{(1,2,8-11)}$. Over a decade of research from Project EAT (Eating Among Teens), a large population-based study of adolescents and their parents, suggests that family meals may help in protecting adolescents from a range of problematic outcomes ${ }^{(3,12-26)}$.

This body of research on family meals has generated much interest from health-care providers, researchers, the media and parents. Parents of adolescents face many barriers in making family meals a reality in their homes and are looking for strategies to address and overcome these challenges. Furthermore, questions are often raised about the nature of the associations between family meals and adolescent health-related outcomes, including questions about what and how strong the associations are; whether associations hold over time; and whether these associations are actually due to family meals or due to underlying differences between families who eat together and those who do not. Given the high level of interest in this topic, the quantity of research on family meals conducted using Project EAT data, the multitude of requests for a summary of Project EAT findings on family meals, and the many questions that have been raised about the meaning of the findings and future research directions, the present paper aims to provide a useful synthesis of the Project EAT research on family meals. 
The paper describes the research process used to explore family meals, summarizes findings from Project EAT-I and Project EAT-II, and suggests future directions for research and interventions. The process of qualitative and quantitative data collection is first described. Key findings are then described regarding: adolescents' perceptions of family meals and obstacles to family meals within their homes; attitudes towards family meals among both adolescents and their parents; family meal frequency across sociodemographic characteristics; and cross-sectional and 5-year longitudinal associations between family meal patterns and dietary intake, disordered eating behaviours, weight status and selected psychosocial outcomes among adolescents. Project EAT findings are then compared with findings from other studies, and implications for further research are discussed.

\section{Methods}

\section{Study design and population}

Project EAT (study waves I and II) included the following phases.

1. Focus groups: Prior to developing the Project EAT survey, twenty-one focus group discussions were conducted with 141 middle-school and high-school adolescents to learn more about factors influencing their food choices and to help inform survey development. Focus groups, which were conducted at schools by trained research staff, were divided by gender and grade level ( 7 th and 10th grade) to have more homogeneity.

2. Project EAT-I: The Project EAT-I study population included 4746 ethnically and socio-economically diverse adolescents from thirty-one public schools in the St. Paul/Minneapolis area. Participants were equally divided by gender (50.2\% boys, $49 \cdot 8 \%$ girls). The mean age of participants was $14 \cdot 9$ years (SD $1 \cdot 7$, range $11-18$ years); $34 \cdot 3 \%$ were in middle school (grades 7 and 8 ) and $65.7 \%$ were in high school (grades 9-12). The participants' ethnic/racial backgrounds were as follows: 48.5\% Caucasian, 19.0\% African-American, 19.2\% Asian-American, 5.8\% Hispanic, 3.5\% Native American and $3.9 \%$ mixed/other. Students completed surveys and height and weight measurements at school during the $1998 / 1999$ school year. Surveys included an $\mathrm{FFQ}^{(27,28)}$ and the Project EAT survey, which assessed an array of socio-environmental, personal and behavioural factors relevant to eating behaviours, weight-related health and overall health.

3. Parent interviews: At the time of the Project EAT-I survey, telephone interviews were conducted with 902 parents of participating adolescents to explore parent eating and weight-related behaviours and the home food environment. Adolescents were stratified by ethnicity/race and were randomly selected from within strata to have their parents interviewed. The majority of interviews (82\%) were conducted with mothers, followed by fathers (9\%), stepmothers and other female guardians (7\%) and other male guardians (2\%).

4. Project EAT-II: A 5-year follow-up study was conducted in 2003-4, in which 2516 of the adolescents and young adults who were part of the original cohort completed mailed surveys, representing $53.0 \%$ of the original cohort and $68.4 \%$ of participants for whom the study had contact information. To account for differential response rates across sociodemographic characteristics, data used in longitudinal analyses were weighted using the response propensity method ${ }^{(29)}$. The weighted estimates are representative of the sociodemographic make-up of the original Project EAT-I sample.

All study protocols were approved by the University of Minnesota Institutional Review Board and by the participating school districts, as appropriate. Study details are described in previous publications ${ }^{(3,5,12,14,30,31)}$ and on the Project EAT website (www.sph.umn.edu/epi/research/EAT).

\section{Survey development and measures}

The development of the Project EAT-I survey was guided by Social Cognitive Theory ${ }^{(32,33)}$, adolescent focus groups ${ }^{(12,21)}$ and a review of existing surveys. The survey was further revised following review by experts in the fields of adolescent health and nutrition and the University of Minnesota Youth Advisory Board. The survey was pilot-tested among 161 middle- and high-school students to determine the test-retest reliability of questions. Comparable items of interest formed the basis for the parent survey. For the Project EAT-II 5-year follow-up study, the Project EAT-I survey was revised and two age-appropriate versions were developed: one for high-school students and one for young adults. Table 1 describes key measures assessing family meal frequency, different aspects of the family meal environment and family connectedness.

\section{Results}

\section{What do family meals look like?}

Findings from focus groups revealed great diversity in family meal patterns, regarding both the frequency and context of family meals ${ }^{(21)}$. While some adolescents described family meals as part of their family's daily routine, others said they hardly ever ate together. Teens described eating meals in various settings including restaurants, around the kitchen table, the living room or alone in the bedroom. Some participants indicated mealtimes were a time for talking with family members while others reported watching television during meals. Furthermore, there were differences in how television was watched during meals; some families watched television together and others watched television while eating in separate rooms. 
Table 1 Description of measures related to family meals in Project EAT (Eating Among Teens)

\begin{tabular}{|c|c|}
\hline Variable & Description of survey item(s) \\
\hline Frequency of family meals & $\begin{array}{l}\text { 'During the past seven days, how many times did all, or most of your family living in your house eat a } \\
\text { meal together?' Six response categories ranged from 'never' to 'more than seven times' }\end{array}$ \\
\hline \multicolumn{2}{|r|}{ 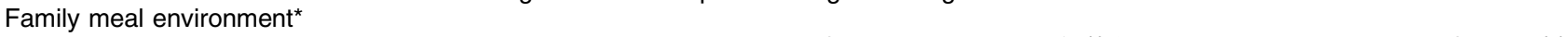 } \\
\hline Family meal atmosphere & $\begin{array}{l}\text { 'How strongly do you agree with the following statements?' (i) 'I enjoy eating meals with my family'; (ii) } \\
\text { 'In my family, eating brings people together in an enjoyable way'; (iii) 'In my family, mealtime is a time } \\
\text { for talking with other family members'; (iv) 'In my family, dinner time is about more than just getting } \\
\text { food, we all talk with each other'. Response categories were 'strongly disagree', 'somewhat disagree', } \\
\text { 'somewhat agree' and 'strongly agree'. Cronbach's } \alpha=0.73\end{array}$ \\
\hline Priority of family meals & $\begin{array}{l}\text { 'How strongly do you agree with the following statements?' (i) 'In my family, it is important that the family } \\
\text { eat at least one meal a day together'; (ii) 'I am often just too busy to eat dinner with my family'; (iii) 'In } \\
\text { my family, different schedules make it hard to eat meals together on a regular basis'; (iv) 'In my } \\
\text { family, it is often difficult to find a time when family members can sit down to a meal together'; (v) 'In } \\
\text { my family, we are expected to be home for dinner'. Response categories were 'strongly disagree', } \\
\text { 'somewhat disagree', 'somewhat agree' and 'strongly agree'. Cronbach's } \alpha=0.82\end{array}$ \\
\hline $\begin{array}{l}\text { Structure/rules at family } \\
\text { meals }\end{array}$ & $\begin{array}{l}\text { 'How strongly do you agree with the following statements?' (i) 'In my family, there are rules at mealtimes } \\
\text { that we are expected to follow'; (ii) 'In my family, it is OK for a child to make something else to eat if } \\
\text { he/she doesn't like the food being served'; (iii) 'In my family, a child should eat all the foods served } \\
\text { even if he/she doesn't like them'; (iv) 'Manners are important at our dinner table'; (v) 'In my family, we } \\
\text { don't have to eat meals at the kitchen/dining room table'. Response categories were 'strongly } \\
\text { disagree', 'somewhat disagree', 'somewhat agree' and 'strongly agree'. Cronbach's } \alpha=0.60\end{array}$ \\
\hline Television viewing at meals & $\begin{array}{l}\text { 'In my family, we often watch television while eating dinner'. Response categories were 'strongly } \\
\text { disagree', 'somewhat disagree', 'somewhat agree' and 'strongly agree' }\end{array}$ \\
\hline Fast food for family meals & $\begin{array}{l}\text { 'In the past week, how many times was a family meal purchased from a fast-food restaurant, and eaten } \\
\text { either at the restaurant or at home?' Six responses ranged from 'never' to 'more than seven times' }\end{array}$ \\
\hline Family connectednesst & $\begin{array}{l}\text { 'How much do you feel you can talk to your mother (father) about your problems?' and 'How much do } \\
\text { you feel your mother (father) cares about you?' Five response categories ranged from 'not at all' to } \\
\text { 'very much'. Cronbach's } \alpha=0.69\end{array}$ \\
\hline
\end{tabular}

${ }^{*}$ Adapted from reference (68).

tSee reference (69).

Focus group discussions also revealed barriers to eating family meals ${ }^{(21)}$. The most frequently mentioned barrier was the schedules of parents and children. Often parents' work schedules caused them to be absent from the home at mealtime or they were too tired to cook when they came home. Adolescents discussed their own activities that interfered with meals, such as work schedules, sports involvement, homework, hanging out with friends and watching television. Another frequently mentioned reason was the desire for increased autonomy, with teens wanting to be on their own or with friends. In spite of these barriers, in nearly all of the focus groups, adolescents said they would eat more healthfully if they ate more meals with their families ${ }^{(21)}$.

The richness of these qualitative data provided an emerging picture of family meals in the homes of adolescents. The diversity across families, barriers to having family meals and the perceived importance of family meals led our research team to explore the topic further. Thus, several measures of family meals were included in the Project EAT survey for teens and interviews with parents.

\section{What do adolescents and their parents think about family meals?}

In general, both parents and adolescents viewed family meals in a positive light, with parents being more positive than adolescents ${ }^{(14)}$. Parents were more likely than adolescents to report higher importance of family meals, better atmosphere at meals, more structure/rules at meals and less television viewing during dinner. For example, about $63 \%$ of adolescents and $98 \%$ of parents agreed with the statements, 'It's important that our family eat a meal together' and 'Eating family meals brings people together in an enjoyable way'. Although there were differences between the parents and their children, responses showed that family meals are perceived positively by both parents and adolescents, suggesting that family meals may be a useful vehicle for enhancing family togetherness.

\section{How frequent are family meals and do they differ by sociodemographic characteristics?} Among middle-school and high-school students, family meal frequency during the past week was as follows: never (14.0\%), 1-2 times (19·1\%), 3-4 times (21.5\%), 5-6 times (18.6\%), 7 times $(8 \cdot 8 \%)$ and more than 7 times $(18 \cdot 0 \%)^{(20)}$. Girls tended to report fewer family meals than boys $(4 \cdot 2 v \cdot 4 \cdot 5$ family meals/week). Family meal frequency was higher among middle-school students than high-school students (5.4 v. 3.9 family meals/week). Asian-American adolescents had the highest frequency of family meals ( $5 \cdot 3$ family meals/week) compared with all other racial groups $(4 \cdot 1-4 \cdot 5$ family meals/week). Family meal frequency was associated with maternal employment status as follows: full time ( 4.2 meals/week), part time ( 4.5 meals/week) and not employed ( 4.9 meals/ week). In general, family meal frequency was positively associated with socio-economic status. 
Differences in family meal patterns across sociodemographic characteristics highlight the importance of adjusting for these variables in analyses examining associations between family meals and adolescent healthrelated outcomes, and being specific about what variables are included as covariates within analyses. Key findings from Project EAT regarding associations between family meals and adolescent outcomes are described in Table 2 and below. In general, analyses were either stratified by, or adjusted for, sociodemographic characteristics such as gender, age, race/ethnicity and socio-economic status. When appropriate, additional covariates were included, such as family connectedness or family weight-related discussions, to ascertain that associations were not due to familial factors other than shared meals. Most other studies investigating associations with family meal frequency have not adjusted for the latter family covariates.

\section{Are family meals associated with better dietary intake?}

Survey results from Project EAT confirmed the perceptions of adolescent focus group participants who indicated they would eat more healthfully if they ate more meals with their families $^{(21)}$. Cross-sectional results showed a positive linear relationship between family meal frequency and dietary intake quality among middle-school and high-school youths. Frequency of family meals was related to higher energy-adjusted intakes of fruit, vegetables, grains, calciumrich foods and several micronutrients, and lower intake of soft drinks ${ }^{(20)}$.

Five-year longitudinal findings further showed that the dietary benefits of eating family meals may persist through adolescence to early young adulthood. Family meals were examined during two major transitions from middle school to high school and from high school to young adulthood. Results adjusting for baseline dietary intake showed that having regular ( $\geq 3$ meals/week) family meals throughout middle school and high school was related to higher intakes of vegetables, calcium-rich foods, fibre and several micronutrients during high school ${ }^{(16)}$. Similarly, family meal frequency during high school predicted lower intake of soft drinks and higher intakes of fruit, vegetables, dark-green and orange vegetables, and key nutrients during young adulthood $^{(25)}$. Having family meals during high school additionally predicted a stronger desire to share meals with other people in young adulthood ${ }^{(25)}$.

Cross-sectional associations between watching television during dinner and dietary intake among middleschool and high-school students were also examined. Among adolescents who had regular family meals $(\geq 3$ meals/week), those who reported often watching television during dinner had higher intakes of soft drinks and fried foods, and lower intakes of dark-green and orange vegetables, and grains ${ }^{(17)}$. Youths who watched television during family meals had more healthful diets on average compared with youths who had no regular family meals, but poorer diets compared with youths who did not watch television during family meals.

A few questions about the types of foods served at family meals were examined in Project EAT, allowing for an initial exploration of associations between the types of foods served at meals and adolescent dietary intake. Parental report of the frequency of purchasing a family meal from a fast-food restaurant was cross-sectionally related to adolescent reports of more frequent overall fast-food consumption ${ }^{(26)}$. Additionally, parental report of serving vegetables at dinner was longitudinally related to higher adolescent vegetable intake five years later ${ }^{(35)}$.

\section{Disordered eating bebaviours and family meals: are family meals protective?}

In cross-sectional analyses, frequent family meals and a positive social environment at family meals were protective against disordered eating behaviours ${ }^{(15)}$. Associations between family meal patterns and unhealthy weight-control behaviours tended to be stronger and more consistent than associations with chronic dieting and binge eating. Furthermore, associations tended to be stronger and more consistent among girls than boys. For example, girls eating 3-4 family meals/week were at about half the odds and girls eating 5 or more family meals/week were at one-third the odds for engaging in extreme weight-control behaviours, including self-induced vomiting and use of diet pills and laxatives, compared with girls reporting no family meals in the previous week.

Longitudinal associations between family meal frequency and disordered eating behaviours were examined to determine the temporality of relationships and to see if associations remained strong over time ${ }^{(23)}$. Even after 5 years, family meals were associated with decreased use of extreme weight-control behaviours in girls. Among boys, family meals were not found to be protective for disordered eating behaviours in longitudinal analyses.

\section{Obesity and family meals: is there an association?}

Associations between family meal frequency and weight status were examined in both cross-sectional and longitudinal analyses stratified by gender and age cohort (middle school $v$. high school at baseline $)^{(19)}$. Significant inverse associations between family meal frequency and overweight status were observed for the younger adolescent females in cross-sectional analyses, but not in the younger males or the older adolescent participants of either gender. In 5-year longitudinal analyses, family meal frequency was not found to be associated with obesity for either age group or gender.

To explore the potential benefits of family meals among overweight adolescents, associations were examined between mealtime contextual variables and an array of behavioural and psychosocial outcomes of particular relevance to this high-risk group ${ }^{(30)}$. Findings showed that a positive mealtime environment was associated with 
Table 2 Key adolescent outcomes found to be correlated with family meals in Project EAT (Eating Among Teens)

\begin{tabular}{|c|c|c|c|c|}
\hline Family meal variable & Outcome & $\begin{array}{l}\text { Cross-sectional } \\
\quad \text { analysis }\end{array}$ & $\begin{array}{l}\text { Longitudinal } \\
\text { analysis }\end{array}$ & Findings \\
\hline Family meal frequency & Dietary intake & $\times$ & & $\begin{array}{l}\text { Frequency of family meals was related to higher intakes of fruit, vegetables, fibre, } \\
\text { protein and various micronutrients, and lower intake of soft drinks among middle- } \\
\text { school and high-school adolescents }(20)\end{array}$ \\
\hline Family meal frequency & Dietary intake & & $\times$ & $\begin{array}{l}\text { Frequency of family meals during middle school and high school predicted better } \\
\text { dietary quality five years later }{ }^{(16,25)} \text {. More frequent family meals were related to } \\
\text { higher intakes of fruit, vegetables, dark-green and orange vegetables, and key } \\
\text { nutrients such as calcium }\end{array}$ \\
\hline $\begin{array}{l}\text { Family meal frequency, } \\
\text { priority, atmosphere } \\
\text { and structure }\end{array}$ & $\begin{array}{l}\text { Disordered eating behaviours } \\
\text { (unhealthy weight-control and } \\
\text { binge eating behaviours) }\end{array}$ & $\times$ & & $\begin{array}{l}\text { Family meal frequency and different aspects of the family meal environment were } \\
\text { inversely associated with disordered eating behaviours in middle-school and high- } \\
\text { school adolescents, particularly among females }\end{array}$ \\
\hline Family meal frequency & Disordered eating behaviours & & $\times$ & $\begin{array}{l}\text { Family meal frequency predicted lower use of extreme weight-control behaviours, } \\
\text { including self-induced vomiting and use of diet pills, laxatives and diuretics, in } \\
\text { females, but not in males, five years later }\end{array}$ \\
\hline Family meal frequency & Overweight/obesity & $\times$ & $\times$ & $\begin{array}{l}\text { Significant inverse associations between family meal frequency and overweight status } \\
\text { were observed for early adolescent females cross-sectionally, but not longitudinally. } \\
\text { No associations were found among older females and males of either cohort }{ }^{(19)}\end{array}$ \\
\hline $\begin{array}{l}\text { Making family meal a } \\
\text { priority and positive } \\
\text { mealtime atmosphere }\end{array}$ & $\begin{array}{l}\text { Emotional well-being (self-esteem, } \\
\text { depressive symptoms, body } \\
\text { satisfaction, unhealthy weight- } \\
\text { control behaviours) }\end{array}$ & $\times$ & & $\begin{array}{l}\text { Among overweight adolescents, making the family meal a priority was significantly } \\
\text { inversely associated with unhealthy weight-control behaviours among both males } \\
\text { and females, as well as with depressed mood among overweight males }{ }^{(30)} \\
\text { A positive mealtime atmosphere was significantly positively associated with self- } \\
\text { esteem among both overweight boys and girls, and with body satisfaction among } \\
\text { overweight boys }{ }^{(30)}\end{array}$ \\
\hline Family meal frequency & Substance use & $\times$ & & $\begin{array}{l}\text { Frequency of family meals was related to lower rates of cigarette smoking, alcohol and } \\
\text { marijuana use. These associations remained significant after adjusting for other } \\
\text { family factors, with the exception of males' marijuana use }\end{array}$ \\
\hline Family meal frequency & Substance use & & $\times$ & $\begin{array}{l}\text { Regular family meals during middle school were associated with lower odds of } \\
\text { cigarette smoking, alcohol and marijuana use for females at follow-up, when they } \\
\text { were in high school. This association was not found for males }\end{array}$ \\
\hline Family meal frequency & $\begin{array}{l}\text { Emotional well-being (self-esteem, } \\
\text { depressive symptoms, suicide } \\
\text { ideation and attempts) }\end{array}$ & $\times$ & & $\begin{array}{l}\text { Frequency of family meals was associated with better self-esteem, fewer depressive } \\
\text { symptoms, and lower rates of suicidal ideation and attempts. After adjusting for } \\
\text { family connectedness and covariates, associations remained significant for females' } \\
\text { depressive symptoms and suicide behaviours, and for males' depressive } \\
\text { symptoms }{ }^{(18)}\end{array}$ \\
\hline $\begin{array}{l}\text { Eating family meal } \\
\text { while watching } \\
\text { television }\end{array}$ & Dietary intake & $\times$ & & $\begin{array}{l}\text { Among youths reporting regular family meals ( } \geq 3 \text { meals/week), watching television } \\
\text { during dinner was related to higher intake of soft drinks and fried foods, and lower } \\
\text { intakes of dark-green/yellow vegetables and grains. However, compared with } \\
\text { youths having no regular family meals, those who had regular family meals and } \\
\text { watched television during dinner reported higher intakes of vegetables and calcium- } \\
\text { rich foods }{ }^{(17)}\end{array}$ \\
\hline $\begin{array}{l}\text { Eating family meal } \\
\text { while watching } \\
\text { television }\end{array}$ & Substance use & $x$ & & $\begin{array}{l}\text { Watching television during family meals did not significantly affect the observed } \\
\text { associations between having regular ( } \geq 3 \text { meals/week) family meals and substance } \\
\text { use }^{(34)}\end{array}$ \\
\hline $\begin{array}{l}\text { Fast food purchased for } \\
\text { family meal }\end{array}$ & Dietary intake & $x$ & & $\begin{array}{l}\text { Parent report of frequently purchasing a family meal from a fast-food restaurant was } \\
\text { related to higher adolescent overall fast-food consumption }\end{array}$ \\
\hline
\end{tabular}


better self-esteem among overweight boys and girls, and with higher body satisfaction among boys. Making the family meal a priority was significantly inversely associated with unhealthy weight-control behaviours among both overweight boys and girls, as well as with depressed mood among overweight boys. These findings suggest that a positive mealtime context can be beneficial for the psychosocial health of overweight youths.

\section{Psychosocial well-being and family meals: do associations extend beyond food?}

In Project EAT-I, family meal frequency was positively associated with adolescent psychosocial well-being ${ }^{(18)}$. More frequent family meals were associated with lower levels of cigarette smoking, alcohol and marijuana use, low self-esteem, depressive symptoms, and suicidal ideation and attempts, for both males and females in unadjusted analyses. After adjusting for family connectedness, parents' marital status and a variety of sociodemographic factors, family meals continued to be protective for all psychosocial outcomes, except for low self-esteem, among females. Males with more frequent family meals continued to have lower levels of cigarette smoking, alcohol use and depressive symptoms.

In Project EAT-II, associations between television viewing during mealtimes and substance-use behaviours were further explored. Respondents were categorized into those who reported regular family meals without television, regular meals with television, and fewer than three weekly family meals, and analyses were adjusted for family connectedness and covariates. Lower prevalences of cigarette smoking, alcohol and marijuana use were found for females reporting regular family meals $v$. no regular family meals ${ }^{(34)}$. However, no significant differences in substance use were found between the groups reporting regular family meals with and without television viewing. These findings suggest that watching television during family meals does not appear to reduce the protective relationship between family meals and substance use.

Longitudinal associations between family meals and substance use were examined to learn more about the temporality of these associations, since cross-sectional associations could be attributed to the fact that adolescents involved in substance use might intentionally avoid meals with family in order to hide or avoid confrontation about their behaviours. More frequent family meals during the middle-school years were associated with lower odds of cigarette smoking, alcohol and marijuana use for females five years later, even after adjusting for baseline substance use and other covariates ${ }^{(24)}$. This finding suggests that regular family meals - or a lack thereof predate involvement in substance-use behaviours for adolescent girls. Interestingly, family meals did not significantly predict substance use among adolescent boys in longitudinal analyses.

\section{Discussion}

Findings from a decade of research on Project EAT indicate diversity in family meal patterns in the homes of adolescents, with regard to both the frequency of family meals and their context. Of concern, about a third of adolescents have two or fewer family meals a week. Scheduling problems of teens and their parents emerged as the key barrier to family meals. In general, adolescents and, even more so, their parents viewed family meals positively; the majority agreed that family meals are important and provide an opportunity for talking with other family members. Family meals were found to be associated with several positive outcomes in adolescents, including better dietary intake, fewer disordered eating behaviours and better psychosocial well-being. In contrast, consistent associations with obesity were not found. Gender differences were apparent; family meals tended to be more strongly associated with disordered eating, substance use, school grades and psychological wellbeing in girls than in boys. Although definitive statements about causality cannot be made and extrapolations to other populations should be made cautiously given that observational data were collected from only one area in the USA, the findings clearly indicate that family meals are associated with an array of positive health-related outcomes in adolescents, both cross-sectionally and longitudinally.

As in Project EAT, other studies consistently suggest that family meals have nutritional benefits for adolescents, despite the use of different family meal measures and the consideration of diverse dietary outcomes (e.g. nutrient intake, intake of fried foods, breakfast frequency, selfefficacy to consume fruit and vegetables) ${ }^{(36-47)}$. While most studies have been cross-sectional, Project EAT also observed longitudinal associations between family meal frequency and dietary intake. The longitudinal associations among the older cohort of Project EAT participants suggest that family meals during adolescence may set a foundation for healthier dietary intakes in early young adulthood.

Project EAT findings are also consistent with other studies suggesting the importance of family meals for preventing or reducing disordered eating behaviours, such as the use of extreme weight-control practices, in youths $^{(48-54)}$. A study using longitudinal data in young black and white girls has further begun to illustrate a potential mechanism through which frequent family meals may help to reduce disordered eating ${ }^{(48)}$. The study, which used data from the National Heart, Lung, and Blood Institute Growth and Health Study, found family meals predicted greater family cohesion and problem-focused coping in girls as they transition from preadolescence through adolescence. Family cohesion and problem-focused coping skills mediated the relationship between having family meals during preadolescence and fewer symptoms of disordered eating during adolescence. 
Studies suggest that the picture regarding associations between family meals and weight status is not clear-cut. Findings from cross-sectional analyses have been mixed; some studies have found associations between family meals and obesity in young adolescents ${ }^{(55,56)}$, while other studies have not found associations ${ }^{(43-45,57)}$ or have found inconsistent associations across different gender and racial/ethnic subgroups ${ }^{(56,58)}$. The null findings of a longitudinal association among adolescents participating in Project EAT add to a small number of previous longitudinal studies, which have also reported mixed or null findings ${ }^{(55,56)}$. The relationship between family meals and weight status may be dependent upon various aspects of the family meal, such as the types and amounts of foods served, rather than solely on the frequency of eating together.

Cross-sectional $^{(51,59)}$ and longitudinal ${ }^{(48,60)}$ studies have found significant associations between family meals and various measures of psychosocial well-being similar to those found in Project EAT. The statistical adjustment for family connectedness in Project EAT is noteworthy, in that it reduces the likelihood that the observed associations are due more generally to positive family functioning, which has been associated with numerous adolescent health behaviours $^{(61,62)}$ as well as family meal frequency. Thus, findings suggest that family meals are associated with positive psychosocial outcomes above and beyond the benefits of family meals for overall family functioning.

\section{Further research questions to be addressed}

The associations between family meals and different health-related outcomes, the strong interest in these findings among professionals and parents, and the gaps in our knowledge about family meals, point to a need for additional research to address the following questions.

1. Are associations between family meals and better adolescent outcomes truly due to family meals? Or are family meals a marker for better family functioning or other familial characteristics not captured by the measures of family connectedness used in Project EAT?

2. What is it about family meals that explains better outcomes in youths? Are the associations due to more consistent monitoring of adolescents and their whereabouts? Are parents who eat with their children more aware of their children's moods because they spend time together for meals on a regular basis? Do family meals provide a setting in which adolescents feel they can discuss topics of concern with their families?

3. Can family meals reduce potential negative influences of peers or neighbourhood characteristics regarding food choices, dieting behaviours, substance use and other outcomes?

4. Why are associations between family meals and obesity inconsistent across studies? Does the type of food available at meals and how it is served make a difference?

5. Why are associations between family meals and different outcomes stronger for some subgroups of adolescents than others? For example, why are associations between family meals and more affective outcomes (e.g. disordered eating, substance use and psychosocial variables) stronger in girls than in boys?

6. What are specific aspects of a family meal that need to happen to make it beneficial? Is the presence of one parent enough? Does it matter whether the shared meal is breakfast $v$. dinner?

7. Do family meals during childhood and adolescence impact the ways in which young adults eat on their own and when they have their own families?

8. How can we most effectively intervene to increase family meal frequency, enhance familial interactions at meals and improve the quality of food served?

In future study waves of Project EAT, we plan to explore many of these questions using multilevel data collected from adolescents and their parents, peers, schools and neighbourhoods. Additionally, we will examine 10-year longitudinal survey data on young adults who participated in Project EAT-I as adolescents. While survey data allow for the study of associations between family meals and various outcomes, qualitative research, including in-home observations of family meals, has the potential to inform us about the intricacies of interactions between family members and details on how food is served, what foods are available, and what topics are discussed at meals ${ }^{(63-65)}$. Intervention studies are also needed in order to determine whether we can, indeed, intervene to improve the frequency and quality of family meals ${ }^{(63-65)}$. Intervention studies, in which changes in both family meals and outcomes are examined, can also help in determining if the associations between family meals and various outcomes are of a causal nature.

\section{Conclusion}

Although additional research is needed, findings from Project EAT and other studies suggest the potential benefits of family meals in helping young people navigate through the challenging period of adolescence. Dietitians and other health-care providers can help adolescents and their parents recognize the importance of family meals and explore ideas for increasing and improving the quality of family meals. Although the responsibility for family meals lies primarily with families, many families will need assistance from the communities where they reside, such as schools, after-school organizations, worksites and food businesses ${ }^{(66,67)}$. The ultimate aim is to help families have the time, skills and resources to share more frequent family meals, a variety of healthy food options and positive social interactions among family members. 


\section{Acknowledgements}

This study was supported by Grants MCJ-27034 and R40 MC 00319 from the Maternal and Child Health Bureau (Title V, Social Security Act), Health Resources and Services Administration, Department of Health and Human Services (Principal Investigator: D.N.-S.). The authors do not have any conflicts of interest related to the content of this manuscript. D.N.-S. is the Principal Investigator on Project EAT and took overall responsibility for writing the manuscript. N.I.L. is the Project Director on Project EAT and wrote parts of the manuscript and developed the tables. J.A.F. contributed to writing the manuscript, particularly the text on family meals and weight status. M.E.E. is a CoInvestigator on Project EAT and contributed to writing the manuscript, particularly the text on family meals and substance use. M.S. is a Co-Investigator on Project EAT and participated in writing the manuscript.

\section{References}

1. DiClemente RJ, Hansen WB \& Ponton LE (1996) Handbook of Adolescent Health Risk Behavior. New York: Plenum Press.

2. Lerner RM \& Steinberg LD (2004) Handbook of Adolescent Psychology, 2nd ed. Hoboken, NJ: John Wiley \& Sons.

3. Neumark-Sztainer D, Story M, Hannan PJ et al. (2002) Overweight status and eating patterns among adolescents: where do youth stand in comparison to the Healthy People 2010 Objectives? Am J Public Health 92, 844-851.

4. Munoz KA, Krebs-Smith SM, Ballard-Barbash R et al. (1997) Food intakes of US children and adolescents compared with recommendations. Pediatrics 100, 323-329. Published erratum appears in Pediatrics (1998) 101, 952-953.

5. Neumark-Sztainer D, Story M, Hannan PJ et al. (2002) Weight-related concerns and behaviors among overweight and non-overweight adolescents: implications for preventing weight-related disorders. Arch Pediatr Adolesc Med 156, 171-178.

6. Kimm SY, Barton BA, Obarzanek E et al. (2002) Obesity development during adolescence in a biracial cohort: The NHLBI Growth and Health Study. Pediatrics 110, e54.

7. Kilpatrick DG, Acierno R, Saunders B et al. (2000) Risk factors for adolescent substance abuse and dependence: data from a national sample. J Consult Clin Psychol 68, 19-30.

8. Worthington-Roberts BS \& Rees JM (1996) Nutrition in adolescence. In Nutrition Throughout the Life Cycle, pp. 316-379 [BS Worthington-Roberts and SR Williams, editors]. St. Louis, MO: Mosby.

9. Smolak L \& Thompson JK (2009) Body Image, Eating Disorders, and Obesity in Youth: Assessment, Prevention, and Treatment, 2nd ed. Washington, DC: American Psychological Association.

10. Eaton DK, Kann L, Kinchen S et al. (2008) Youth risk behavior surveillance - United States, 2007. MMWR CDC Surveill Summ 57, 1-131.

11. Kessler RC \& Walters EE (1998) Epidemiology of DSM-III-R major depression and minor depression among adolescents and young adults in the National Comorbidity Survey. Depress Anxiety 7, 3-14.

12. Neumark-Sztainer D, Story M, Perry C et al. (1999) Factors influencing food choices of adolescents: findings from focus-group discussions with adolescents. J Am Diet Assoc 99, 929-937.
13. Neumark-Sztainer D, Wall M, Eisenberg ME et al. (2006) Overweight status and weight control behaviors in adolescents: longitudinal and secular trends from 1999-2004. Prev Med 43, 52-59.

14. Fulkerson JA, Neumark-Sztainer D \& Story M (2006) Adolescent and parent views of family meals. J Am Diet Assoc 106, 526-532.

15. Neumark-Sztainer D, Wall M, Story M et al. (2004) Are family meal patterns associated with disordered eating behaviors among adolescents? J Adolesc Health 35, 350-359.

16. Burgess-Champoux TL, Larson NI, Neumark-Sztainer D et al. (2009) Are family meal patterns associated with overall diet quality during the transition from early to middle adolescence? J Nutr Educ Behav 41, 79-86.

17. Feldman S, Eisenberg M, Neumark-Sztainer D et al. (2007) Associations between watching TV during family meals and dietary intake among adolescents. J Nutr Educ Behav 39, 257-263.

18. Eisenberg ME, Olson RE, Neumark-Sztainer D et al. (2004) Correlations between family meals and psychosocial wellbeing among adolescents. Arch Pediatr Adolesc Med 158, 792-796.

19. Fulkerson JA, Neumark-Sztainer D, Hannan PJ et al. (2008) Family meal frequency and weight status among adolescents: cross-sectional and 5-year longitudinal associations. Obesity (Silver Spring) 16, 2529-2534.

20. Neumark-Sztainer D, Hannan PJ, Story M et al. (2003) Family meal patterns: associations with sociodemographic characteristics and improved dietary intake among adolescents. J Am Diet Assoc 103, 317-322.

21. Neumark-Sztainer D, Story M, Ackard D et al. (2000) The 'family meal': views of adolescents. J Nutr Educ 32, 329-334.

22. Neumark-Sztainer D, Story M, Ackard D et al. (2000) Family meals among adolescents: findings from a pilot study. J Nutr Educ 32, 335-340.

23. Neumark-Sztainer D, Eisenberg ME, Fulkerson JA et al. (2008) Family meals and disordered eating in adolescents: longitudinal findings from Project EAT. Arch Pediatr Adolesc Med 162, 17-22.

24. Eisenberg ME, Neumark-Sztainer D, Fulkerson JA et al. (2008) Family meals and substance use: is there a long-term protective association? J Adolesc Health 43, 151-156.

25. Larson NI, Neumark-Sztainer D, Hannan PJ et al. (2007) Family meals during adolescence are associated with higher diet quality and healthful meal patterns during young adulthood. J Am Diet Assoc 107, 1502-1510.

26. Boutelle K, Fulkerson JA, Neumark-Sztainer D et al. (2007) Fast food for family meals: relationships with parent and adolescent food intake, home food availability and weight status. Public Health Nutr 10, 16-23.

27. Rockett HRH, Breitenbach MA, Frazier AL et al. (1997) Validation of a youth/adolescent food frequency questionnaire. Prev Med 26, 808-816.

28. Rockett HR, Wolf AM \& Colditz GA (1995) Development and reproducibility of a food frequency questionnaire to assess diets of older children and adolescents. J Am Diet Assoc 95, 336-340.

29. Little RJA (1986) Survey nonresponse adjustments for estimates of means. Int Stat Rev 54, 139-157.

30. Fulkerson JA, Strauss J, Neumark-Sztainer D et al. (2007) Correlates of psychosocial well-being among overweight adolescents: the role of the family. J Consult Clin Psychol 75, 181-186.

31. Neumark-Sztainer D, Wall M, Haines J et al. (2007) Shared risk and protective factors for overweight and disordered eating in adolescents. Am J Prev Med 33, 359-369.

32. Baranowski T, Perry CL \& Parcel GS (2002) How individuals, environments, and health behavior interact: 
Social Cognitive Theory. In Health Behavior and Health Education: Theory Research and Practice, 3rd ed., pp. 165-184 [K Glanz, BK Rimer and FM Lewis, editors]. San Francisco, CA: Jossey-Bass.

33. Bandura A (1986) Social Foundations of Thought and Action: A Social Cognitive Theory. Englewood Cliffs, NJ: Prentice-Hall, Inc.

34. Eisenberg ME, Neumark-Sztainer D \& Feldman S (2009) Does TV viewing during family meals make a difference in adolescent substance use? Prev Med 48, 585-587.

35. Arcan C, Neumark-Sztainer D, Hannan P et al. (2007) Parental eating behaviours, home food environment and adolescent intakes of fruits, vegetables and dairy foods: longitudinal findings from Project EAT. Public Health Nutr 10, 1257-1265.

36. Gillman MW, Rifas-Shiman SL, Frazier AL et al. (2000) Family dinner and diet quality among older children and adolescents. Arch Fam Med 9, 235-240.

37. Videon TM \& Manning CK (2003) Influences on adolescent eating patterns: the importance of family meals. $J$ Adolesc Health 32, 365-373.

38. Granner M, Sargent R, Calderon K et al. (2004) Factors of fruit and vegetable intake by race, gender, and age among young adolescents. J Nutr Educ Behav 36, 173-180.

39. Befort C, Kaur H, Nollen N et al. (2006) Fruit, vegetable, and fat intake among non-Hispanic black and non-Hispanic white adolescents: associations with home availability and food consumption settings. J Am Diet Assoc 106, 367-373.

40. Ayala G, Baquero B, Arredondo E et al. (2007) Association between family variables and Mexican American children's dietary behaviors. J Nutr Educ Behav 39, 62-69.

41. Kusano-Tsunoh A, Nakatsuka H, Satoh H et al. (2001) Effects of family-togetherness on the food selection by primary and junior high school students: family-togetherness means better food. Tohoku J Exp Med 194, 121-127.

42. Veugelers P \& Fitzgerald A (2005) Prevalence of and risk factors for childhood overweight and obesity. CMAJ 173, 607-613.

43. Mamun AA, Lawlor DA, O'Callaghan MJ et al. (2005) Positive maternal attitude to the family eating together decreases the risk of adolescent overweight. Obes Res $\mathbf{1 3}$ $1422-1430$.

44. Utter J, Scragg R, Schaaf D et al. (2008) Relationships between frequency of family meals, BMI and nutritional aspects of the home food environment among New Zealand adolescents. Int J Behav Nutr Phys Act 5, 50.

45. Yuasa K, Sei M, Takeda E et al. (2008) Effects of lifestyle habits and eating meals together with the family on the prevalence of obesity among school children in Tokushima, Japan: a cross-sectional questionnaire-based survey. J Med Invest 55, 71-77.

46. Woodruff SJ \& Hanning RM (2008) A review of family meal influence on adolescents' dietary intake. Can J Diet Pract Res 69, 14-22.

47. Woodruff SJ \& Hanning RM (2009) Associations between family dinner frequency and specific food behaviors among grade six, seven, and eight students from Ontario and Nova Scotia. J Adolesc Health 44, 431-436.

48. Franko D, Affenito S, Thompson D et al. (2008) What mediates the relationship between family meals and adolescent health issues? Health Psychol 27, 2 Suppl., S109-S117.

49. Crowther JH, Kichler JC, Sherwood NE et al. (2002) The role of familial factors in bulimia nervosa. Eat Disord $\mathbf{1 0}$, 141-151.

50. Ackard D \& Neumark-Sztainer D (2001) Family mealtime while growing up: associations with symptoms of bulimia nervosa. Eat Disord 9, 239-249.
51. Fulkerson JA, Story M, Mellin A et al. (2006) Family dinner meal frequency and adolescent development: relationships with developmental assets and high-risk behaviors. $J$ Adolesc Health 39, 337-345.

52. Miller DAF, McCluskey-Fawcett K \& Irving LM (1993) Correlates of bulimia nervosa: early family mealtime experiences. Adolescence 28, 621-635.

53. Worobey J (2002) Early family mealtime experiences and eating attitudes in normal weight, underweight and overweight females. Eat Weight Disord 7, 39-44.

54. Mellin AE, Neumark-Sztainer D, Patterson J et al. (2004) Unhealthy weight management behavior among adolescent girls with type 1 diabetes mellitus: the role of familial eating patterns and weight-related concerns. J Adolesc Health 35, 278-289.

55. Taveras E, Rifas-Shiman S, Berkey C et al. (2005) Family dinner and adolescent overweight. Obes Res 13, 900-906.

56. Sen B (2006) Frequency of family dinner and adolescent body weight status: evidence from the national longitudinal survey of youth, 1997. Obesity (Silver Spring) 14, 2266-2276.

57. Mikkila V, Lahti-Koski M, Pietinen P et al. (2003) Associates of obesity and weight dissatisfaction among Finnish adolescents. Public Health Nutr 6, 49-56.

58. Gundersen C, Lohman B, Eisenmann J et al. (2008) Childspecific food insecurity and overweight are not associated in a sample of 10- to 15-year old low-income youth. J Nutr 138, 371-378.

59. Compañ E, Moreno J, Ruiz MT et al. (2002) Doing things together: adolescent health and family rituals. J Epidemiol Community Health 56, 89-94.

60. Fisher LB, Miles IW, Austin SB et al. (2007) Predictors of initiation of alcohol use among US adolescents: findings from a prospective cohort study. Arch Pediatr Adolesc Med 161, 959-966.

61. Resnick MD, Bearman PS, Blum RW et al. (1997) Protecting adolescents from harm: findings from the National Longitudinal Study on Adolescent Health. JAMA 278, 823-832.

62. Kingon YS \& O'Sullivan AL (2001) The family as a protective asset in adolescent development. J Holist Nurs 19, 102-121.

63. Johnson DB, Birkett D, Evens C et al. (2006) Promoting family meals in WIC: lessons learned from a statewide initiative. J Nutr Educ Behav 38, 177-182.

64. Rosenkranz RR \& Dzewaltowski DA (2009) Promoting better family meals for girls attending summer programs. $J$ Nutr Educ Behav 41, 65-67.

65. Fulkerson JA, Rydell S, Kubik MY et al. (2008) Healthy Home Offerings Via the Mealtime Environment (HOME): feasibility, acceptability, and initial results of a pilot study. Presented at Seventh Annual Meeting of the International Society for Behavioral Nutrition and Physical Activity, Banff, Canada, 20-23 June 2008.

66. Story M \& Neumark-Sztainer D (2005) A perspective on family meals: do they matter? Nutr Today 40, 261-266.

67. Fiese BH \& Schwartz M (2008) Reclaiming the family table: mealtimes and child health and wellbeing. In Social Policy Report: Giving Child and Youth Development Knowledge Away, pp. 3-9. Washington, DC: Society for Research in Child Development.

68. Hogen PD (1988) The relationship between individual psychological characteristics and factors associated with family use of food as predictors of disturbed eating attitudes and behaviors in adolescents. Doctoral Dissertation, University of Hartford, p. 208.

69. Resnick MD, Harris LJ \& Blum RW (1993) The impact of caring and connectedness on adolescent health and wellbeing. J Paediatr Child Health 29, Suppl. 1, S3-S9. 